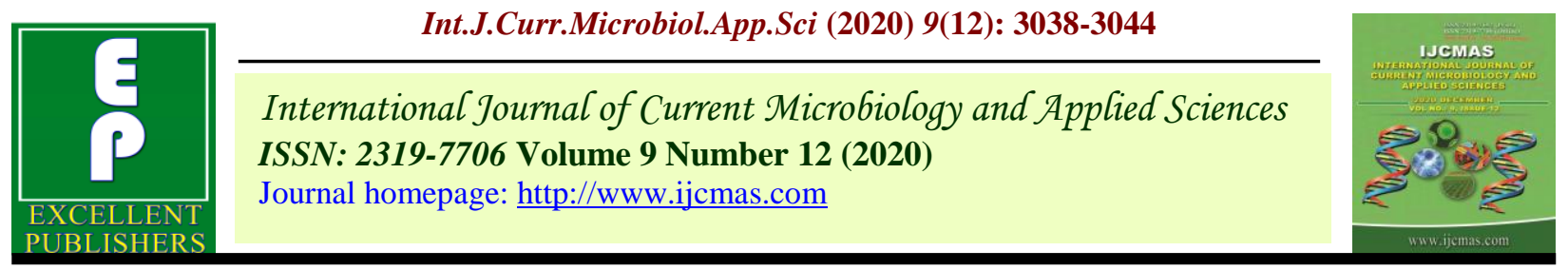

Original Research Article

https://doi.org/10.20546/ijcmas.2020.912.360

\title{
Trend Analysis of Rainfall and Rainy Days using Mann Kendall Method and Sen's Slope Estimator in Parola Tehsil of Jalgaon District of Maharashtra (India)
}

\author{
Kundan M. Kamble*, V.A. Sthool, S.K. Upadhye, J.D. Jadhav, \\ S.V. Bagade and A.M. Giri \\ Mahatma Phule Krishi Vidyapeeth, Rahuri, Dist. Ahmednagar, Maharashtra, India \\ *Corresponding author
}

\section{A B S T R A C T}

Keywords

Mann Kendall method, Sen's slope method, Rainfall, Rainy days, Trend analysis

Article Info

Accepted:

22 November 2020

Available Online:

10 December 2020
The study has been carried out to investigate and assess the significance of the potential trend of rainfall and rainy days over the Parola tehsil of Jalgaon district of Maharashtra. This study focuses on detecting trends in annual, seasonal and monthly precipitation for the Jalgaon district. For this study, the widely used modified Mann- Kendall test run at a 5\% significance level on time series data for each of the years for the period, 1961 to 2018. Mann-Kendall test and Sen's slope estimate test were applied to identify the existing trend direction and Sen's slope estimator test was used to detect the trend direction and magnitude of change over time. The test results showed increasing rainfall and rainy days trend over the Parola tehsil for annual, seasonal and monthly (May to November) time series.

\section{Introduction}

Precipitation is the key climatic variable that affects both the spatial and temporal patterns of water resources. Analyzing the long-term trends and variability of rainfall is very important for sustainable water resources management. Studying the trends of precipitation has enormous use for researchers to describe the suitable cropping pattern. Trend analysis of rainfall is also essential to study the impacts of climate change for water resources planning and management. The changes in the most important climatological parameter i.e. rainfall. Rainfall is the dominant single weather element influencing the intensity and location of the farming system and the choice of enterprise.

Rakhecha and Soman (1994) reported that 'the extreme rainfall series at stations over the southern Peninsula and over the lower Ganga valley showed a decreasing trend at $95 \%$ level of confidence. Some past studies related to changes in rainfall over India have concluded that there is no clear trend in average annual rainfall over the country (Thapliyal and Kulshreshtha, 1991; Kumar et al., 2010). 
Parthasarathy and Dhar (1974) found that the annual rainfall for the period 1901-1960 had a positive trend over Central India and the adjoining parts of the peninsula. A stable northeast monsoon rainfall was found over Tamil Nadu by Dhar et al., (1982). Analysis of rainfall amount during different seasons indicated decreasing tendency in the summer monsoon rainfall over the Indian land mass and increasing trend in the rainfall during pre monsoon and post-monsoon months (Dash et al., 2007).

According to Goswami et al., (2006) the frequency of more intense rainfall events in many parts of Asia has increased whereas the number of rainy days and total annual precipitation has decreased. Variability and long-term trends of extreme rainfall events over central India were examined by Rajeevan et al., (2008) using 104 years (1901-2004) of high-resolution daily gridded rainfall data. They found statistically significant long-term trend of $6 \%$ per decade in the frequency of extreme rainfall events. According to them, the increasing trend of extreme rainfall events in the last five decades could be associated with the increasing trend of sea surface temperatures and surface latent heat flux over the tropical Indian Ocean. Analysis of daily gridded observed rainfall data for the period 1951-2003, indicated that there are decreasing trends in both early and late monsoon rainfall and number of rainy days, implying a shorter monsoon over India. Similarly, there is a sharp decrease in the area that receives a certain amount of rainfall and number of rainy days during the season (Ramesh and Goswami, 2007).

India is highly influenced by the southwest monsoon. According to Guhathakurta and Rajeevan (2008), although average annual rainfall in the country is $119.4 \mathrm{~cm}$, about 60 $\%$ of the country's total cultivable land remains as rainfed. Many parametric and non- parametric tests were used to reveal the trend is present in the rainfall records. One of the popular non-parametric tests widely used for detecting trends in the time series is the Mann-Kendall test (Mann, 1945 and Kendall, 1975). The trends of maximum rainfall and rainy days are analyzed for meteorological data of Jalgaon district in Maharashtra, India during the period 1961 to 2018 obtained from India Meteorological Department (IMD) and state department of Agriculture. The longterm change in rainfall and rainy days are analyzed by correlation and linear trend analysis.

The Maharashtra state is prominently agriculture-based. However, the share of the agriculture sector in the state's gross domestic production is less than $25 \%$. The rainfall received in an area is an important factor in determining the amount of water available to meet various demands, such as agricultural, industrial and domestic water supply.

The Maharashtra state which is to the northwest of peninsular is facing water scarcity almost every year hence the trend analysis was carried out to examine the long term trends in rainfall over different subdivisions. The rainfall trend is very crucial for better economic development, hydrological planning and adaptation for extreme events.

The tehsil receives highest percent of rain from the South-West monsoon from June to September month. July is the month of the highest rainfall.. The rainfall is heavier in the hilly range of the northern part of the district. Hence, we can have three broad divisions as far as rainfall concerned (i) the northern zone receiving heavy and assured rainfall (ii) the central zone receiving moderate rainfall and (iii) the southern zone receiving low, irregular and uncertain rainfall. 


\section{Materials and Methods}

\section{Study area and data availability}

Parola tehsil is found in northern region of Maharashtra lying between $20^{\circ}-53^{\prime}$ north latitude, and $75^{\circ}-07$ ' east longitude. It covers an estimated area of $780 \mathrm{~km}$.

\section{Data sources}

Daily rainfall data were collected from Department of Agricultural Meteorology, College of Agriculture, Pune, India Meteorological Department, Pune and Downloaded from www.maharain.gov.in (www.krishi.maharashtra.gov.in) from the month of January to December for the period fifty eight years from 1961 to 2018.

\section{Software/Programme}

Microsoft office sub-module MS-Excel was used for data analysis and MAKESENS excel template was used for trend detection and estimation of magnitude of trend (Salmi et al., 2002)

\section{Rainfall and rainy days trend analysis}

Trend analysis (increase or decrease) of annual rainfall and rainy days was statistically examined by the non-parametric MannKendall method and Sen's slope method.

\section{Mann-Kendall Test}

Compare first-year data point with $2^{\text {nd }}$, $3^{\text {rd }}, \ldots . . ., 58^{\text {th }}$-year data point.

Assign,

+1 if $\mathrm{X} 1<\mathrm{X} 2$

-1 if $X 1>X 2$

0 if $\mathrm{X} 1=\mathrm{X} 2$
The Sum of assigned values will give MannKendall Statistic (S).

A very high value of Mann-Kendall Statistic is an indicator of an increasing trend and a very low negative value indicated a decreasing trend. However, it is necessary to compute the probability associated with Mann-Kendall Statistic and the sample size, $\mathrm{n}$, to statistically quantify the significance of the trend. The Mann-Kendall test statistics is calculated using the formula,

$\mathrm{S}=\sum_{\mathrm{k}-1}^{\mathrm{n}} \sum_{\mathrm{j}-\mathrm{k}-1}^{\mathrm{n}} \operatorname{sign}(\mathrm{Xj}-\mathrm{Xk})$.

Where,

$\mathrm{X}_{\mathrm{j}}$ and $\mathrm{X}_{\mathrm{k}}$ are the annual values in years $\mathrm{j}$ and $\mathrm{k}, \mathrm{j}>\mathrm{k}$ respectively,

$\mathrm{X}_{\mathrm{k}}$ represents the data point at time $\mathrm{k}$.

The value of sign $\left(\mathrm{x}_{\left.\mathrm{j}-\mathrm{x}_{\mathrm{k}}\right)}\right)$ is computed as the number follows:

1 if $x_{j}-x_{k}>0$
0 if $x_{j}-x_{k}=0$
-1 if $x_{j}-x_{k}<0$

This statistic represents the number of positive differences minus the number of negative differences for all the differences considered. For large samples $(\mathrm{N}>10)$, the test is conducted using a normal approximation $(\mathrm{Z}$ statistics) with the mean and the variance as follows:

Variance $(S)=\frac{\frac{\left(n(n-1)(2 n+5)-\sum_{p=1}^{p=g}(t p(t p-1)(2 t p+5))\right.}{18}}{18}$

Where,

$\mathrm{n}=$ number of years,

$\mathrm{g}=$ number of tied groups

(A tied group is a set of sample data having the same value) 
tp $=$ number of items in the tied group

Calculate a normalized test statistic $\mathrm{Z}$ by the following equation,

$\mathrm{z}=\frac{(\mathrm{S}+1)}{\sqrt{\text { Varience }}(\mathrm{S})} \quad$ If $\mathrm{S}>0$

$\mathrm{z}=0 \quad$ If $S=0$

$\mathrm{Z}=\frac{(\mathrm{S}-1)}{\sqrt{\text { Varience }(S)}} \quad$ If $S<0$

Where, $\quad \mathrm{S}=\mathrm{p}-\mathrm{q}$

$\mathrm{p}=$ number of $(+1)$ values and

$\mathrm{q}=$ number of $(-1)$ values

The presence of a statistically significant trend is evaluated using the $\mathrm{Z}$ value. A positive value of $\mathrm{Z}$ indicates an upward trend and its negative value a downward trend. The statistic $\mathrm{Z}$ has a normal distribution. In the present study, at a confidence level of 99, 95, and 90 per cent the positive or negative trends are determined by the test statistic.

\section{Sen's Slope Method}

To derive an estimate of the slope $\mathrm{Q}_{\mathrm{t}}$, Sen's slope method was used for predicting the magnitude of hydro-meteorological time series data. This method uses a linear model for the trend analysis by using a simple nonparametric procedure developed by Sen (1968) the slope of all data pairs is calculated by

$\mathrm{Q}_{\mathrm{t}}=^{\frac{x_{j}-X k}{j-k}}, \mathrm{i}=1,2,3, \mathrm{~N}, \mathrm{j}>\mathrm{k}$

Where,

$x_{j}$ and $x_{k}$ are the data values for $j$ and $k$ times of a period and $j>k$.
The slope is estimated for each observation. If there are ' $n$ ' values of $X_{j}$ in the time series then as many as $\mathrm{N}=\mathrm{n}(\mathrm{n}-1) / 2$ slope estimates, $\mathrm{Q}_{\mathrm{t}}$ is to be computed. The Sen's estimator of the slope is the median of these $\mathrm{N}$ values of $\mathrm{Q}_{\mathrm{t}}$. The $\mathrm{N}$ values of $\mathrm{Q}_{\mathrm{t}}$ are ranked from the smallest to the largest and the Sen's estimate is calculated as,

$Q_{t}=\left\{\begin{array}{cl}Q \frac{N+1}{2} & \text { If } N \text { is odd } \\ \frac{1}{2}\left(Q \frac{N}{2}+Q \frac{N+2}{2}\right. & \text { If } N \text { is even }\end{array}\right.$

The median of all slope values gives $Q$, which is the magnitude of a trend. A positive value indicates increasing and negative values indicate a decreasing trend of rainfall and rainy days.

\section{Result and Discussion}

The Mann Kendall trend, its statistical significance along with magnitude of Sen's slope for 1961 to 2018 year rainfall and rainy days data is shown in Table 1 (Fig. 1 and 2).

\section{Annual rainfall and rainy days trend analysis}

The test results showed that annual rainfall $(Z=2.91)$ and rainy days $(Z=-0.28)$ were increasing at the significance level of 99 per cent and decreasing respectively over 58 years. The $Q$ statistics showed nature of annual rainfall trends at Parola tehsil were significantly increasing.

\section{Seasonal rainfall and rainy days trend analysis}

The south west rainfall trend contribute highest was significant increasing, for south west monsoon $(Z=3.01)$ at 99 per cent confidence level summer $(Z=-0.17)$, north east monsoon $(Z=-0.73)$ and winter shows decreasing $(Z=-0.17)$. The $Q$ statistics showed nature of rainfall trends at Parola 
tehsil during summer, south west monsoon and winter were decreasing. The rainy days trend was decreasing, for the summer $(\mathrm{Z}=$ $0.40)$, winter $(Z=-0.38)$, south west monsoon
$(\mathrm{Z}=-0.03) .$. The $\mathrm{Q}$ statistics showed nature of rainy days trends at Parola tehsil during south west monsoon were significantly increasing.

Table.1 Rainfall and rainy days trend analysis at Parola tehsil

\begin{tabular}{|c|c|c|c|c|c|c|c|}
\hline \multicolumn{2}{|c|}{ Time series } & \multicolumn{3}{|c|}{ Rainfall (mm) } & \multicolumn{3}{|c|}{ Rainy Days } \\
\hline \multirow{2}{*}{\multicolumn{2}{|c|}{ Annual }} & Test $\mathrm{Z}$ & Signific. & $\mathbf{Q}$ & Test $\mathrm{Z}$ & Signific. & $\mathbf{Q}$ \\
\hline & & 2.91 & $* *$ & 3.56 & -0.28 & & 0 \\
\hline \multirow[t]{4}{*}{ Seasonal } & Winter & -0.17 & & 0 & -0.38 & & 0 \\
\hline & Summer & 0.60 & & 0 & -0.40 & & 0 \\
\hline & SW & 3.01 & $* *$ & 3.322 & -0.03 & & 0 \\
\hline & $\mathrm{NE}$ & 0.73 & & 0.136 & 0.25 & & 0 \\
\hline \multirow[t]{7}{*}{ Monthly } & May & -0.15 & & 0 & -0.41 & & 0 \\
\hline & June & 0.87 & & 0.44 & 0.47 & & 0 \\
\hline & July & 1.10 & & 0.53 & 0.24 & & 0 \\
\hline & August & 1.48 & & 0.74 & -0.89 & & -0.02 \\
\hline & September & 2.31 & $*$ & 1.24 & 0.22 & & 0 \\
\hline & October & 0.62 & & 0 & 0.37 & & 0 \\
\hline & November & 0.23 & & 0 & 0.23 & & 0 \\
\hline
\end{tabular}

*Significance at 95 per cent confidence level, ** Significance at 99 per cent confidence level and + Significance at 90 per cent confidence level

Fig.1 Seasonal trend in rainfall and rainy days

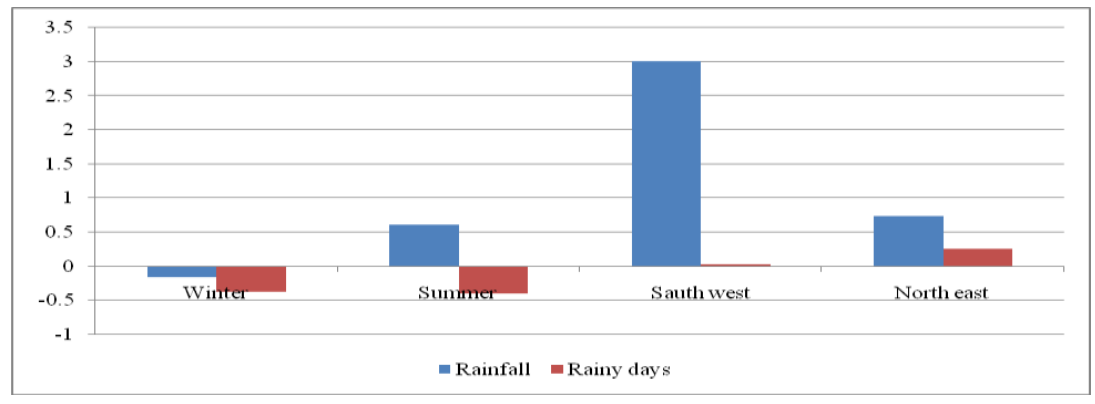

Fig.2 Monthly trend in rainfall and rainy days

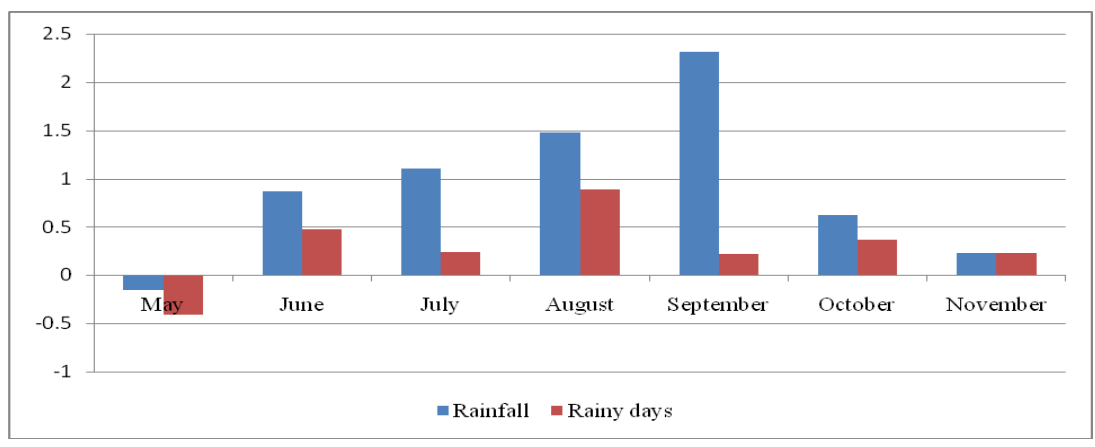


Monthly rainfall and rainy days trend analysis

The monthly rainfall trend was decreasing, for May $(Z=-0.15)$. September shows increasing with $(Z=2.31)$ at 90 per cent level of significance. The $\mathrm{Q}$ statistics showed nature of rainfall trends at Parola tehsil during September were increasing. The monthly rainy days trend was decreasing, for May $(\mathrm{Z}=$ $-0.41)$ and August $(Z=-0.89)$. The $Q$ statistics showed nature of rainy days trends at Parola tehsil during May and August were decreasing.

In conclusions the annual rainfall and data showed increasing trend in Parola all seasons of tehsil $\mathrm{s}$ shows increasing trend except winter season. The seasonal rainfall trend showed significantly increasing trend for south west seasons. The monthly rainfall trend showed increasing trend for June, July, August, September, October and November months and the monthly rainy days trend showed decreasing trend in May and august month.

\section{Abbreviation}

$\mathrm{Km}$ : Kilometre; $\mathrm{Km}^{2}$ : Kilometre square; ${ }^{0} \mathrm{~N}$ : Degree North, ${ }^{0} \mathrm{E}$ : Degree East; IMD: India Meteorological Department; No.: Number; mm: Millimetre; Signific: Significant; et al.: and others; SW: southwest; NE: Northeast and ha: Hector.

\section{Acknowledgment}

The authors would like to thank the Department of Agricultural Meteorology, College of Agriculture, Pune; Maharain portal, Government of Maharashtra and India Meteorology Department for providing the raw meteorological data. This work would not have been possible without the support and guidance of Dr. J. D. Jadhav Head, Dept of
Agril. Meterology College of Agril. Pune for their valuable insight and analysis.

Author Contributions: All authors equally contributed.

Author statement: All authors read, reviewed, agreed and approved the final manuscript.

Conflict of Interest: The authors declare no conflict of interest.

\section{References}

Dash, S. K., Jenamani, R. K., Kalsi, S. R. and Panda, S. K., 2007, "Some evidence of climate change in twentieth-century India", Climatic Change, 85, 299-321.

Dhar, O. N., Rakhecha, P. R. and Kulkarni, A. K., 1982, "Fluctuations in northeast monsoon rainfall of Tamil Nadu", Int. J. Climatol., 2, 339-345.

Goswami B. N., Venugopal V., Sengupta, D., Madhusoodanan, M. S. and Xavier, P. K.,2006, "Increasing trend of extreme rain events over India in a Warming", Environment. Science, 314, 1442-1445.

Guhathakurta, P. and Rajeevan, M. 2008. Trends in the rainfall pattern over India. International Journal of Climatology.28: 1453-1469.

Kendall M. G. (19750. Rank Correlation methods, Charles Griffin, London.Kumar, V., Jain, S. K. and Singh, Y., 2010, "Analysis of long-term rainfall trends in India", Hydrol. Sci. J., 55, 484-496.

Mann H.B. (1945). Non-parametric test against trend. Econometrica (13): 245-259. Parthasarathy, B. and Dhar, O. N., 1974, "Secular variations of regional rainfall over India", Q. J. R. Meteorol. Soc., 100, 245257.

Rajeevan, M., Bhate, J. and Jaswal, A. K., 2008, "Analysis of variability and trends of extreme rainfall events over India using 
104 years of gridded daily rainfall data", Geophys. Res. Lett., 35, L18707.

Rakhecha, P. R. and Soman, M. K., 1994, "Trends in the annual extreme rainfall events of 1 to 3 days duration over India", Theor. Appl. Climatol., 48, 227-237.

Ramesh, K. V. and Goswami, P., 2007, "The shrinking Indian summer monsoon", Research Report RR CM 0709, CSIR Centre for Mathematical Modelling and Computer Simulation, Bangalore.

Thapliyal, V. and Kulshreshtha, S. M., 1991, "Climate changes and trends over India",
Mausam, 42, 333-338.

Salmi, T., Maatta, A., Anttila P., Airola, R., and Amnell, T. 2002. Detection trends of annual values of atmospheric pollutants by the Mann Kendall test and Sen's slope estimates the Excel template application MAKESENS. Finnish Meteorological Institute Air Quality Research (1-35).

Sen P. K. (1968). Estimation of regression co efficient based on Kendall's test. Journal of American Statistical Association, Vol. 63:1379-1389.

\section{How to cite this article:}

Kundan M. Kamble, V.A. Sthool, S.K. Upadhye, J.D. Jadhav, S.V. Bagade and Giri, A.M. 2020. Trend Analysis of Rainfall and Rainy Days using Mann Kendall Method and Sen's Slope Estimator in Parola Tehsil of Jalgaon District of Maharashtra (India). Int.J.Curr.Microbiol.App.Sci. 9(12): 3038-3044. doi: https://doi.org/10.20546/ijcmas.2020.912.360 